\title{
Insight
}

\section{The Problem of Scale in Indigenous Knowledge: a Perspective from Northern Australia}

\author{
Marc Wohling ${ }^{1}$
}

\begin{abstract}
Over the last decade, indigenous knowledge has been widely touted by researchers and natural resource managers as a valuable contributor to natural resource management and biodiversity conservation. In Australia, the concept of indigenous knowledge has gained such rapid currency that it has tended toward an essentialized and universal truth rather than remaining a diverse range of highly localized and contested knowledge. In this paper, I undertake a critical analysis of some of the current issues around the interpretation and application of indigenous knowledge and its relationship with natural resource management in northern Australia. Through a focus on how indigenous knowledge operates at a range of scales, I argue that indigenous knowledge is not adapted to the scales and kinds of disturbances that contemporary society is exerting on natural systems. Rather than being realistic about the limitations of indigenous knowledge, I argue that nonindigenous interpretations of indigenous knowledge have propelled us toward reified meanings, abstracted concepts, and an information-based taxonomy of place. The result can be the diminishing and ossifying of a dynamic living practice and the failure to recognize expressions of indigeneity in contemporary forms.
\end{abstract}

Key Words: decision making; ecological scale; ecology; ethnoecology; indigenous knowledge; natural resource management; northern Australia.

\section{INTRODUCTION}

"Northern Australia" is a generic term used to loosely describe the desert, tropical savannas, and wet tropic landscapes of Queensland, Western Australia, and the Northern Territory, north of the Tropic of Capricorn (latitude 23.5 ${ }^{\circ} \mathrm{S}$ ). In June 2001, the indigenous population of Australia was estimated to be 460,140 , or $2.4 \%$ of the total population, with $64 \%$ in northern Australia (Australian Bureau of Statistics 2002). In northern Australia the majority of Aboriginal and Torres Strait Islander people continue to live on their traditional lands in remote settlements and outstations, which are small clan-based groups on homelands. The clan group and extended family still forms the basic social unit (Altman and Whitehead 2003, National Native Title Tribunal 2006). The Tropical Savannas bioregion covers much of northern Australia, i.e., $15 \%$ of Australia's area, and has a total population of approximately 200,000 people of which $25 \%$ is Aboriginal (Holmes 1996).
Approximately $76 \%$ of the Australian coastline is under statutory customary ownership. The Australian government recognizes that indigenous Aboriginal and Torres Strait Islander Australians are major stakeholders in the management and protection of Australia's natural and cultural resources (DEH 2006).

Indigenous ecological knowledge (IEK), or indigenous knowledge (IK) as it is more commonly known, has gained currency as an essential key to the management of northern Australian landscapes (North Australia Indigenous Land and Sea Management Alliance 2004, 2006a). In addition, over the last $10 \mathrm{yr}$ there has been mounting concern by both indigenous people and nonindigenous people about the loss of IK and how to mitigate this loss (Langton 1999, North Australia Indigenous Land and Sea Management Alliance 2004, 2006b, Cochrane 2005, Pannell 2005, Dhimurru 2006). In the apparent headlong rush to preserve IK there has been little consideration as to its social context, its 
inherent paradoxes, its clear definition, whether such knowledge existed, and if it did, how it existed and was transferred in its current social context.

Recent global debates on the validity of IK in natural resource management (NRM) raise many questions about its applicability as a "stand-alone" NRM regime (Brosius 1997, Berkes 1999, Cunningham 2001, Wohling 2001, Johannes 2002, Du Toit et al. 2003, Jinxiu et al. 2004, Gilchrist et al. 2005, Rose 2005, North Australia Indigenous Land and Sea Management Alliance 2006b). In northern Australia, it has been widely acknowledged that indigenous connection to the landscape has many complex layers and interrelationships with ecology, identity, kinship, social organization, governance, and economy (Morphy 1991, Langton 1999, Rose 2000, Merlan 2004). Although it is unquestioned that local knowledge, or local IK, is an important repository of information about the natural history of specific indigenous estates, there is mounting empirical and theoretical evidence that IK is not adapted to the scales and kinds of disturbance that contemporary society is exerting on natural systems (Du Toit et al. 2003, Bohensky and Lynam 2005, Cundill et al. 2005, Gilchrist et al. 2005, Frazer et al. 2006).

In northern Australia it has almost become de rigueur to include an IK component in new NRM projects or ecological research, often without regard to the degree of knowledge that actually exists in the particular region in question and if it does, whether local people's knowledge is capable of managing the often-broadscale ecosystem change that has occurred (Altman and Whitehead 2003, Balkanu Cape York Development Corporation 2006, DEH 2006, NAIF 2006, Tropical and Coastal Knowledge Research Hub 2006).

The rise in recognition of IK in Australia has also been accompanied by a popular perception that, if local communities are empowered to do so, they will use their local knowledge to manage their natural resources sustainably (Christie 1990, Storrs and Cooke 2001, Altman and Whitehead 2003, North Australia Indigenous Land and Sea Management Alliance 2004, Rose 2005, Tropical and Coastal Knowledge Research Hub 2006). However, there has been little discussion or debate as to whether this will occur, how IK operates at different scales, and how indigenous people's agency plays out in NRM decision making on indigenous landscapes (Pannell 2005).
It appears the more IK is championed by nonindigenous people, the more it is co-opted by them and becomes a reified, abstracted universal concept of ecological knowledge and an information-based taxonomy of place (Brosius 1997, Cruikshank 1998, Ruddle 2001). The effects of this can be a focus on indigenous people's historical relationship to their local landscape and the "branding" of that relationship as IK. As nonindigenous people become increasingly preoccupied with the search for authentic IK, the greater their misunderstanding of contemporary indigeneity becomes. As northern Australian landscapes face increasing pressures from contemporary society, such correlations are unhelpful in assisting indigenous people to manage their landscape in a contemporary setting (Verran 2002, Russell-Smith et al. 2003b, Whitehead et al. 2003).

Indigenous people in northern Australia own large tracts of land for which they have custodial responsibility (Baker et al. 1993, Langton 1999, Altman and Whitehead 2003, Russell-Smith et al. $2003 b$, North Australia Indigenous Land and Sea Management Alliance 2004). However, many of these areas have been depopulated for long periods since colonization. This trend is set to continue as indigenous people struggle to reconcile a huntergatherer based economy with a market-based economy, and recent Australian federal government policy has encouraged further relocation to urban areas (Altman 2000, Russell-Smith et al. 2003b, Taylor 2006).

As a result, the focus of knowledge building about the northern Australian landscape has changed. There is considerable debate as to whether that there can be a "going back" to the way landscapes were pre-European colonization (Bowman et al. 2003, Fisher et al. 2003, Russell-Smith et al. 2003a,b, Whitehead et al. 2003). Change to the state and condition of northern Australia landscapes is rapidly reaching the point of being irreparable, and the focus of key environment and conservation agencies is shifting to management approaches that improve, maintain, and repair what landscape integrity remains (Department of Environment and Conservation 2007). At the same time considerable resources are being directed to aspects of IK research that may be better-used assisting indigenous people in managing current pressures on northern Australian landscapes. The recent opening of the United Nations Institute of Advanced Studies Centre for Traditional Knowledge in Darwin, 
Northern Territory, indicates that the issues raised in this paper are timely (Charles Darwin University 2007).

How indigenous people's identity, culture, and knowledge manifest amidst such change and how this plays out in a contemporary context has become a key, yet largely unidentified issue in Australian NRM. It is well documented that colonization has had a profound impact on indigenous people in Australia (Langton 1999, Altman 2000, Rose 2000, Folds 2001, Wohling 2001, Verran 2002, Merlan 2004). The resultant uneasy relationship between indigenous and nonindigenous people means that the difficulty of managing change in the socioecological systems of northern Australian landscapes may increase without further consideration of the aforementioned issues.

In this paper, I primarily focus on the debate as to whether IK is capable of operating at the kinds of scales required to manage the broad range of threatening processes present in northern Australian landscapes. I use scale as a context to situate the ongoing debates around IK in current NRM practice.

\section{DEFINING INDIGENOUS KNOWLEDGE}

Before one can examine the scales at which IK operates, one must first define what we mean by IK. The deceptively simple task of how to "name" IK has been the source of considerable debate (Brosius 1997, Cruikshank 1998, Berkes 1999, Gilchrist et al. 2005). It continues to be variously referred to as Aboriginal science, ethnoscience, traditional ecological knowledge, indigenous ecological knowledge, indigenous knowledge systems, folk ecology, ethnoecology, indigenous intellectual and cultural property, cultural knowledge, and local knowledge. In this paper I have chosen the term indigenous knowledge, because it is the generally accepted usage in Australia. However, there is still debate over this term. Cruikshank (1998) questioned the use of the term indigenous to describe something as precise as local knowledge:

Cultural knowledge is learned and passed on locally and does not inhere in reified political categories. However, once the term indigenous knowledge becomes ideologically embedded, it gets welded to other ideas that inevitably sweep up local views in its vortex. What may be overlooked is local knowledge-learned, shared, and passed on locally, and this may be a more helpful characterization (Cruikshank 1998:49).

Along with the multitude of terms for indigenous knowledge is the rapidly developing pool of international literature on the topic. The literature is from a broad range of geographic regions and disciplines and represents an alarming trend to uncritically accept indigenous knowledge as an ideological critique (Brosius 1997, Cruikshank 1998):

The sheer scope of the literature raises questions about whether a growing tendency to present indigenous knowledge as somehow free-standing to give what one student of African agriculture has called 'spurious epistemic independence' may be propelling us away from questions about what can be learned from local knowledge and toward assigning reified meanings to abstract concepts (Cruikshank 1998:48).

The consequences of the rising interest in IK have been a multitude of interpretations of its meaning by various academic disciplines and a preoccupation with its structural and systematic nature (Brosius 1997). Each discipline brings its own set of assumptions, and indigenous knowledge is variously compartmentalized as ecological, spiritual, cultural, or traditional, existing as a static and cultural relic from an idealized past; all of these framed within a post-colonial debate (Gupta 1998, Sluyter 2002, Verran 2002).

The interest in IK has occurred as part of an ongoing historical narrative of western engagement with indigenous societies and the other. Indigenous people's rights have been increasingly recognized and more and more opportunities are arising for their participation in decision making about their future. What was once "stone-age culture," "native superstition," or "witchdoctor magic," now takes the stage as a respectable catchall term IK (Brosius 1997, Langton 1999).

Indigenous people have been relieved of their primitive and stone age identities only to be burdened with an equally irksome and romanticized new identity of "spiritual wisdom and ancient ecological knowledge" (Brosius 1997, Langton 1999). The discourse on indigenous people as the keepers of some form of magical, sacred, and 
ancient knowledge has resulted in a semantic sleight of hand that transforms indigenous knowledge into a politicized discourse amenable to a diverse range of interest groups such as environmentalists, nationalists, new age spiritualists, and dare I say it, ecological and social researchers (Brosius 1997).

The result has been the co-opting and compartmentalizing of IK, taking what is essentially a varied and dissimilar array of local, secret, and sacred knowledge and transforming it into a universal wisdom. In Australia, the result has been a lack of debate about exactly what the limitations of IK are in regard to contemporary natural resource management. Somewhat more disturbing are attempts to apply highly localized and contested sets of knowledge to landscape-scale threatening processes.

\section{INDIGENOUS KNOWLEDGE AND THE PROBLEM OF SCALE}

The question of scale and the lack of debate on the role of IK in NRM and biodiversity conservation at various scales have had a number of effects. At present in northern Australia there is no single clear definition of IK, rather it has become caught up in a hermeneutic loop of definitions. As I have argued, this has resulted in its transmutation into a reified "universal truth" in which IK is seen as an unchanging continuum of knowledge through time. IK has thus become deified as a "fix-all" solution for NRM and ecological issues at all scales of landscape management. Major research programs in northern Australia commonly cite IK as a key part of the research paradigm (North Australia Indigenous Land and Sea Management Alliance 2004, Northern Land Council 2005, NAIF 2006, Tropical and Coastal Knowledge Research Hub 2006, Charles Darwin University 2007).

If we accept the notion that one's knowledge is bounded by one's culture and physical cultural space then a problem arises. One's knowledge of a landscape is based not only on this "cultural boundedness" but also set of assumptions learned over a specific period in a specific place. Indigenous people living on their traditional landscapes estimate probabilities on a continuous basis in the search for resources (Rose 2000, Gilchrist et al. 2005, Martinez-Balleste et al. 2006). However, whether this type of consideration can be regarded as scientific method requires considered and careful debate (Brook and McLachlan 2005, Gilchrist et al. 2005). If one's lifetime spent resource gathering in a particular area is during a particular geological period or climatic cycle such as an El Nino or La Nina cycle or a period of climate change, one's assumptions and intuitive estimates for probabilities will be greatly influenced and bounded by these experiences and the physical place one inhabits in the landscape. A change occurring in one's local area does not necessarily correlate to widespread change at the landscape scale.

It is here that the danger lies in the current application of IK to landscape-scale threatening processes and management. Experiential knowledge may become redundant if broad landscape-scale changes are occurring in the surrounding regions but not on one's home patch or traditional estate. The inverse can also apply when localized change may be occurring on one's patch but not to any great extent in the broader landscape. The counterintuitive method available in western science and applicable across a range of scales is not readily apparent in IK (Gilchrist et al. 2005). Problems in IK can also occur when future generations inherit a changed landscape, yet their inherited knowledge base is unable to explain these changes, or there has been a loss of IK for the particular region in question.

A good example of this phenomenon is the rapid extinction of the small- to medium-sized mammals in the central deserts and parts of the tropical savannas of North Australia (Finlayson 1943, Burbidge et al. 1988, Woinarski et al. 2001). These extinctions have occurred in native mammals with a critical weight range of between $35 \mathrm{~g}$ to $5500 \mathrm{~g}$ (Burrows et al. 2006). More than one third of the terrestrial mammal species in the deserts of central Australia have become extinct over the last $50 \mathrm{yr}$ (Burbidge et al. 1988). Many senior indigenous knowledge holders in central Australia believed that these species had disappeared because they had left when "whitefellas" had arrived or that whitefellas had removed all these animals from their landscapes and now kept them in zoos in large cities in the south (Finlayson 1943, Burbidge et al. 1988, Wohling and Gambold 1997, Wohling 2000, Burrows et al. 2006). It was believed that these animals would thrive once again if they were returned to their traditional country.

From 1997-2000, I conducted an ethnoecological project with Pintupi people in the western desert in which I examined the disappearance of critical 
weight range (CWR) mammals in detail. During this project I was able to confirm the findings of previous studies on the belief by the Pintupi that these species had "decided to leave" or had been removed by whitefellas. Further, I was able to confirm the apparent disjuncture between the Pintupi's impressive ecological understanding of their landscape, however, their reluctance to acknowledge the subtle yet massive changes that underlay the CWR extinctions. There was clear acknowledgement of a changed fire regime and of the arrival of feral animals, but the connection between these factors and the mammal extinctions was not a theory that was generally accepted by the Pintupi (Wohling and Gambold 1997, Wohling 2001, Burrows et al. 2006). This was despite the fact that many of the senior men had made specific observations about landscape change such as the rabbit often colonized native species burrow systems and foxes and cats predated on CWR species. Often the inverse was the case: the feral cat and the rabbit were welcomed as new sources of food, and the cat was adopted into the Pintupi's mythological universe and was assigned its own Tjukurrpa, i.e., dreaming story.

When undertaking field surveys for over $3 \mathrm{yr}$, we were able to draw upon local IK to identify new populations of Greater Bilby (Macrotis lagotis) within the Gibson Desert. During presurvey participatory sessions, senior knowledge holders identified sites on a map at which they had observed Bilby populations. The discovery of these populations, previously unknown to scientists, provides a good example of how IK and scientific knowledge can work together but also that there is a disjuncture between the systems. Researchers have been somewhat slow to acknowledge Pintupi claims about existing CWR populations and their local knowledge about these species, despite that profound knowledge has been demonstrated for over $50 \mathrm{yr}$ of engagement with scientists (Finlayson 1943, Burbidge et al. 1988, Wohling 2001). The difficulty was that once we had found new populations of, for example the Bilby, many old Pintupi men believed that the Bilby was once again thriving throughout the broader landscape and that there was no need for any further research or intervention. Based on what they saw as observable fact (yutirringinyi, i.e., visible therefore real, apparent increasing populations of Bilby), they believed that the Bilby was now secure. I was often hard-pressed to convince these old men that these populations were in fact remnant populations and in danger of disappearing, as demonstrated by substantial and wide-ranging aerial and on-ground surveys by scientists, and by the appalling record of extinctions of CWR mammals.

This provides a clear example of a key unresolved issue for IK; one of scale and its transferability from a local to regional or landscape scale. Managing or undertaking ecological research on a particular landscape is largely about weighing up and attempting to understand the probabilities of change, and of cause and effect, through application of the scientific method (Berkes 1999, Gilchrist et al. 2005). Western science has produced a scientific method and a set of universal laws and axioms such as statistical theory, evolutionary and ecological theory, tectonic plate theory, and meteorology, etc., which are applicable at a global scale, whereas IK is by definition highly local, differentiated and contested knowledge (Hunn 1999, Gilchrist et al. 2005). Although the IK of senior Pintupi was profoundly impressive at the local scale, i.e., within the clan estate, senior Pintupi were more akin to supercharged naturalists rather than to ecological scientists. It is this very localness, boundedness, and fine-scale focus that makes IK highly intuitive and thus often lacking in the counter-intuition that is the cornerstone of modern ecological science and necessary for operability at the large scale. The Pintupi were able to provide valuable ecological knowledge about CWR species at the local level. It is arguable whether IK has the capacity to measure, understand, and predict the probabilities for change at the broader landscape scale.

\section{BROADER ISSUES AROUND FRAMING INDIGENOUS KNOWLEDGE AT THE LANDSCAPE SCALE}

In northern Australia, the profound impact of colonization has not been uniform. Some indigenous societies managed to remain on their traditional estates and remain largely intact, whereas others were dispossessed and were highly fragmented (Langton 1999, Rose 2000, Verran 2002, Russell-Smith et al. 2003b, Aboriginal Areas Protection Authority/Northern Land Council 2004, Merlan 2004, Wohling and Daly River Aboriginal Reference Group 2006). In some cases indigenous societies were wiped out all together, or the survivors were absorbed into a neighboring group. In these instances a process of succession took place whereby the neighboring group took on custodial responsibilities for the adjoining estates (Stanner 
1979, Rose 2000, Russell-Smith et al. 2003b, Merlan 2004, Wohling and Daly River Aboriginal Reference Group 2006).

As I have outlined, this has resulted in a number of distortions in the way indigenous people manage their landscapes and has even led to acrimonious disputes amongst indigenous groups about how indigenous estates should be managed (Wohling and the Daly River Aboriginal Reference Group 2006). For the dispossessed, a lack of access to their traditional estates has left many of these estates unoccupied and largely unmanaged (Storrs and Cooke 2001, Russell-Smith et al. 2003b, Northern Land Council 2005). In addition, a number of generations of Aboriginal people in northern Australia have grown up on or around cattle stations over the last $100 \mathrm{yr}$ (McGrath 1987). The influence of pastoralist land management techniques on indigenous people is an area of research that has yet to be fully investigated (Russell-Smith et al. 2003b).

For the fortunate who were able to remain on their land, the long-term interaction with western science and NRM, rarely on equitable terms, has often resulted in the embedding of a western conception of IK into local knowledge (Yibarbuk 1998). This raises a number of difficult but interesting debates that highlight these distortions and the problematic nature of discussions about IK. I would also argue that it has led to the misguided attempts to apply IK at a landscape scale and a paternalistic habit of including IK into all large-scale scientific research projects when its relevance is sometimes questionable (North Australia Indigenous Land and Sea Management Alliance 2004, NAIF 2006, Tropical and Coastal Knowledge Research Hub 2006).

For indigenous people in northern Australia, cultural and ecological knowledge have become the keystones for demonstrating an ongoing connection to their traditional estates (Langton 1999). In Australia, the postcolonial era resulted in a legal situation in which indigenous people have had to prove their prior ownership, i.e., land rights, through the western legal system, and they have had to demonstrate an ongoing connection to their lands through maintenance of cultural and ecological knowledge (Langton 1999, Altman 2000). The result has been an often-lengthy legal process and a protracted, bitter, and not always successful land rights struggle (Langton 1999, Altman 2000). Consequently, discussions about the distorting effect of colonization on IK can be highly emotive and fraught with difficulty. However, I would argue that these are necessary debates if our engagement with IK is to evolve and indigenous people are to achieve real equity in how their estate is managed.

At the heart of this debate lie the key interlinking issues of authenticity, identity, and culture, and their relationship to ecological knowledge. I have argued that local knowledge is bounded both physically in time and space by a group's physical landscape and metaphorically by culture. For example, knowledge of the harvesting, preparation, and usage of a particular plant or animal species is handed down through generations. As in the example of the bilby, local IK is often at a loss to explain broadscale landscape change and its effect on local mammal populations. A similar situation applies to the sea turtle populations of the northern coast of Australia. Although coastal indigenous people have a sometimes profound knowledge at the estate level, for example the natural history of the Green turtle (Chelonia mydas), they have limited understanding of the broader life histories of this species such as the long-range migration routes and the genetic relationships between international populations (Australian Fisheries Management Authority and National Oceans Office 2003, North Australia Indigenous Land and Sea Management Alliance 2004, Smyth and Bahrdt 2004). It is through the work of combined science and IK projects that indigenous people now have a broader understanding of the complexities of the life history of $C$. mydas and the threatening processes that confront it (Australian Fisheries Management Authority and National Oceans Office 2003, North Australia Indigenous Land and Sea Management Alliance 2004, Northern Land Council 2005). IK alone is unable to operate at the enormous scale required to conserve and manage such a migratory species (Australian Fisheries Management Authority and National Oceans Office 2003).

An ecosystem is dynamic and not static and uniform. If the landscape or seascape in question undergoes subtle changes over time or through natural catastrophe or ecosystem perturbations how relevant does the natural history of that plant or animal remain through generations? The massive structural change wrought on northern Australian landscapes by colonization may render much of IK redundant. Species and ecosystems respond differently to change. At the landscape scale these changes may not be perceivable or explainable by 
local knowledge. Knowledge of the name and use of a plant does not equate to an understanding of the ecological drivers of that plant's life history or to the broader threatening processes it may face at the landscape scale.

Indigenous societies adapt and evolve in response to colonization. As indigenous people continue to evolve and adapt their knowledge of postcolonial landscapes, hybrid knowledge, derived from a mix of indigenous and nonindigenous knowledge is created. I argue that the preoccupation with the search for authentic IK has been something of a yellow brick road. What can be transferred between generations is the summary codified information about a particular plant or animal but the ecology of the plant or animal species in question must be learnt experientially by each generation in situ over time. Consequently, I would argue that 30-yr knowledge is not the same as 2000-yr knowledge. The older knowledge, codified as information in a summary form is passed to the next generation who then interpret it based on current conditions (Wohling 2000, 2001, Frazer et al. 2006). What requires recognition is the way indigenous people adapt to change by absorbing new understandings of their estate. These new forms remain a valid expression of contemporary indigeneity. It is frequently nonindigenous people who insist on framing indigeneity and IK through the lens of the past and then attempt to extrapolate this authentic knowledge out as universal axioms or truths.

Another key debate framing the question of IK's operability at various scales: is there a broad-based set of principles one can derive from highly localized and differentiated sets of local ecological knowledge that are applicable to landscape-scale management?

One of the most contentious debates in northern Australian NRM has been on fire management of the savannas and desert landscapes (Duff and Braithwaite 1989, Yibarbuk 1998, Bowman et al. 2001, 2003, Yibarbuk et al. 2001, Russell-Smith et al. 2003b, Whitehead 2003). Indigenous people across both the savannas and deserts managed their estates through regular burning. In the tropics it was most commonly in the early dry season. In the desert, although burning could occur at any time, it would primarily occur in the high summer. However, historically, the spatial extent and pattern of indigenous burning is still not clearly known (Duff and Braithwaite 1989, Russell-Smith et al. 2003b). Burning regimes have been the source of a great deal of research that has both involved and excluded indigenous landowners to varying degrees (Langton 1999, Dyer et al. 2001, Russell-Smith et al. 2003b, Whitehead et al. 2003). One of the outcomes of this research has been attempts to extrapolate out a broad based set of IK principles to apply across the savannas landscape despite an acknowledged lack of understanding of the spatial extent and pattern of past indigenous burning regimes. An ideology has arisen around indigenous fire regimes that have precluded debate about the validity of applying IK techniques to the landscape scale. I argue that the lack of constructive debate around the limitations of IK is a further manifestation of nonindigenous paternalism that only constrains indigenous aspirations to manage their traditional estates.

An unfortunate consequence of colonization has been the introduction of feral animals, invasive species of weeds, and a European fire regime of mid- to late-season fires that are large-scale and highly intense (Bowman et al. 2001, Duff and Braithwaite 1989, Russell-Smith et al. 2003a). Additionally, some areas have remained unburnt for decades because of depopulation (Altman and Whitehead 2003, Russell-Smith et al. 2003a, Whitehead et al. 2003). The effect has been that much of the vegetation of the savannas has undergone structural change (Bowman et al. 2001, Woinarskiet al. 2001, Russell-Smith et al. 2003b, Department of Environment and Conservation 2007). As a result, local knowledge of burning in these new conditions is a highly contested arena of debate (Yibarbuk 1998, Russell-Smith et al. 2003a, Whitehead et al. 2003). In a great irony, after decades of being ignored, indigenous people now find land managers and government agencies attempting to apply somewhat hazy principles of IK in an overly prescriptive manner that may prove detrimental because of the structural change to vegetation. Indigenous people argue that both indigenous and nonindigenous land managers are, in some instances, now burning incorrectly, e.g., too frequently in the same areas and/or at the wrong time (Yibarbuk 1998, Wohling 1997-2000, Yibarbuk et al. 2001, Russell-Smith et al. 2003b, Whitehead et al. 2003, Northern Land Council 2005).

The fire debate in northern Australia provides a good example of the co-opting and institutionalizing of a social process. Indigenous fire knowledge now 
reified is at risk of being universalized into a broadbased set of principles and applied in an overly prescriptive manner at the landscape scale. The danger lies in a "forgetting" of its operability at the fine scale and the highly contested arena from which it emerged.

\section{THE ISSUES CREATED BY ESSENTIALIZING INDIGENOUS KNOWLEDGE}

The preoccupation solely with ecological knowledge has had the effect of divorcing IK from its social and cultural context, i.e., its social process. The result has been a misunderstanding of both the historical and contemporary social conditions in which it was created. In addition, the researcher's penchant for the taxonomic has turned an experiential knowledge into information: a series of word, species, and place lists and summary codified forms that when removed from their specific context render them largely meaningless (Verran 2002).

The well-meaning co-opting of IK by the academy has also had a tendency to place a great deal of expectation on indigenous people in northern Australia to "produce" IK. The result can be the creation of a "cultural self-consciousness" whereby knowledge can be manufactured to appease nonindigenous researchers. In some instances there have been accusations by indigenous people of intergroup and intragroup borrowings and alleged theft of cultural and/or ecological knowledge (Wohling and the Daly River Aboriginal Reference Group 2006), particularly in circumstances in which a local indigenous descent group has suffered a major impact from colonization. The result has been an increasingly acrimonious debate amongst many disenfranchised indigenous groups about what constitutes authentic and inauthentic culture and which group or individual possesses an authentic culture and knowledge (Merlan 2004, Wohling and Daly River Aboriginal Reference Group 2006).

However, a lack of authentic IK does not necessarily correlate with poor decision making by indigenous people about landscape management. A refusal to accept that indigenous people have agency in decision making on NRM issues despite suffering a loss of cultural knowledge continues to be a major stumbling block in the engagement between indigenous and nonindigenous people in northern Australia. The struggle for validity for those disenfranchised indigenous groups that have returned to their traditional lands, or continue to remain estranged from them, is an emerging issue in the management of northern Australian landscapes that has received little attention.

One of the most unfortunate consequences of this issue has been the misunderstanding of the needs of indigenous NRM managers. Many of the indigenous statutory bodies responsible for overseeing NRM on large tracts of land throughout northern Australia continue to rely on a complex patchwork of small short-term grants to survive (Northern Land Council 2005, North Australia Indigenous Land and Sea Management Alliance $2006 b$ ). It remains an unfortunate paradox that although successive Australian federal governments have demanded indigenous people in remote areas seek employment; these same government have failed to recognize the employment potential and real achievements of the many community-based ranger programs (Langton 1999, Altman and Whitehead 2003, Whitehead et al. 2003, Cochrane 2005, Kimberley Land Council 2006). I argue that the preoccupation with the preservation of IK by both indigenous and nonindigenous people has contributed to the obfuscating of the contemporary work being done on indigenous landscapes by indigenous people; work that frequently involves a mixture of both western and local knowledge. Shortterm grant applications must often be framed in "flavor of the month/term of government" language (North Australia Indigenous Land and Sea Management Alliance 2006b). The continued uncritical use of terms such as IK contributes to the perpetuation of this funding paradigm. Further, Aboriginal English phraseology such as "Caring for Country" has become a key term in expressing the complex relationship of indigenous people to their estates. I argue that although useful as a "bridging" term for the initial conveying of the indigenous conception of estate stewardship, such terms now serve to radically over simplify this complex, contested, and rapidly evolving realm. I argue that such terms have now become unhelpful, contributing to ongoing stereotyping of Aboriginal people.

We are left with a paradox. The call for more IK programs results in government, institutions, and researchers becoming increasingly prescriptive about what remains an elusive and intangible form of knowledge. The voices of indigenous people are lost in the ensuing chimera. Many indigenous 
people feel they cannot contradict, question, or disagree with researchers (Wohling and the Daly River Aboriginal Reference Group 2006). This has the effect of placing them in the awkward position in which they may feel pressured to manufacture some form of IK or risk feeling deeply ashamed at their perceived lack of authenticity or validity as indigenous people and keepers of cultural and/or ecological knowledge (Wohling and the Daly River Aboriginal Reference Group 2006).

If we accept that indigenous people have agency then we must also accept that indigenous people can make NRM good decisions about their landscapes and correspondingly, may sometimes make decisions that are not in the best interests of their landscape. Nonindigenous people, anxious to assign some form of useful role to indigenous people, have refused to acknowledge that indigenous people also express agency through disinterest and nonparticipation. I argue that part of accepting the role of IK in NRM is also accepting that not all indigenous people possess IK, not all IK is valid, and not all indigenous people are interested in IK or in becoming natural resource managers.

Rather than relegating indigenous people to being museum pieces there must be an acceptance of indigenous people's right to choose how they participate in management of their landscapes and what knowledge they choose to absorb and adapt to their land management needs. An indigenous group wishing to set up a cattle station is a valid expression of indigeneity. To avoid local knowledge losing its multidimensionality and capacity to evolve, greater attention should be paid to the current work of indigenous landscape managers and the provision of adequate resourcing and support. This would be a far more effective means of facilitating cultural resilience. Current indigenous management regimes can best be described as contemporary NRM, or indigenous NRM, a healthy mix of western science and indigenous local knowledge (Altman and Whitehead 2003, Whitehead et al. 2003, Cochrane 2005, North Australia Indigenous Land and Sea Management Alliance 2006b, Wohling and the Daly River Aboriginal Reference Group 2006).

\section{CONCLUSIONS}

Kalam themselves partly explain their hunting orientation in historical terms, arguing plausibly that it is only recently that they have turned over to pig husbandry and the extensive gardening that this entails. However, the continuing importance of the forest and of hunting lies also in their symbolic opposition to cultivation, human domestic activity, and the man-made landscape; in the identification of the forest with fertility and continuity; and the value set on hunting as a male pursuit (Majnep and Bulmer 1977:37).

It is undeniable that a number of indigenous groups in northern Australia still possess a large and impressive storehouse of local knowledge about their specific estates. However, there has been scant consideration of how applicable such knowledge is, to managing current NRM problems at the landscape scale. Similarly, how indigenous people's identity, culture, and knowledge play out in a contemporary context has become a key, yet largely unidentified issue in NRM. The question of validity in IK may be a yellow brick road particularly when indigenous people have had long exposure to western society and ideas.

Furthermore, there has been little discussion about how those groups who have lost IK but continue to work as effective land managers can be assisted and how to frame their knowledge (Australian Fisheries Management Authority and National Oceans Office 2003, Pannel 2005, North Australia Indigenous Land and Sea Management Alliance 2006b). There has been little attention paid to the social conditions in which knowledge occurs. The nonindigenous preoccupation with IK and its accompanying epistemological debates should not be a priority when many Australian indigenous societies are ripped apart by social dysfunction, substance abuse, poor health, poor education, and poverty.

Perhaps a first step is to recognize that indigenous people have agency. One of the simplest ways of doing this is to identify good ideas in landscape management and to provide adequate resources that will enable indigenous people to get on with the business of managing their lives and landscapes. Indigenous people will choose for themselves the way in which they will manage, transfer, and recreate knowledge in a contemporary context. Both indigenous and nonindigenous NRM managers and researchers should be alert to our own prescriptiveness. The preoccupation with the search for authentic IK has the effect of branding indigenous people's relationship with the landscape 
into a particular dimensionality and undermining indigenous agency and validity in a contemporary setting.

We cannot go back to the way the landscapes were prior to European arrival. Rather we need to facilitate good and effective management of the current situation and look forward. In northern Australia, there are many excellent examples of indigenous people getting on with the job often in very difficult circumstances and creating an amalgamated form of western scientific and local knowledge (Altman and Whitehead 2003, Australian Fisheries Management Authority and National Oceans Office 2003, Whitehead et al. 2003, Cochrane 2005, North Australia Indigenous Land and Sea Management Alliance 2006b). Is this new form of new knowledge IK? I do not know. IK is not a universal knowledge but in fact a diverse range of differentiated and highly localized knowledge. Maybe we need to abandon such terms as IK altogether; instead referring to it as local knowledge, a particular local group's knowledge, or simply contemporary NRM or indigenous NRM.

Nonindigenous researchers should be mindful of the social conditions in which knowledge occurs and of the importance of improving health and education, working with young people, and looking at new and innovative ways to improve literacy and numeracy as a way of supporting resilience (Christie 1990, Cochrane 2005, North Australia Indigenous Land and Sea Management Alliance 2006b). This can occur while still recognizing and respecting the old. Just "doing science" on indigenous lands is no longer acceptable. As ecologists working on the indigenous estate, we should also facilitate understanding and transfer of our scientific knowledge to strengthen indigenous resilience (Cunningham 2001, Laird 2002, Verran 2002, Frazer et al. 2006).

As the first flush of excitement and enthusiasm for IK in northern Australia wanes, perhaps we need to bring our expectations into balance. IK might help us understand some things but not everything. It is not I am afraid, the key to the universe but one of many. Culture, knowledge, and identity are inextricably linked to the dynamic nature of society. Documenting IK forms an important part maintaining the continuum of indigenous connection to the landscape but should not become an isolated focus. We should look to the now and support and work with the new ways of being that are being presented to us by indigenous people. Recognizing that indigenous people are already expressing their identity and long-held connection to their traditional estates through contemporary forms is a first step in the right direction.

The future for engagement in NRM between nonindigenous researchers and indigenous people rests in a considered and contested approach in the same way other disciplines and ways of being are debated, evaluated, and evolved through discourse and practice.

Responses to this article can be read online at:

http://www.ecologyandsociety.org/voll4/iss 1/art1/responses/

\section{Acknowledgments:}

I thank Dr. Amanda Harris, Professor Bruce Campbell, Dr. Tony Cunningham, and Dr. Bevelyn Sithole for the debates and comments on draft manuscripts. Professor Richard Baker also made useful comments on early drafts. I also thank the anonymous reviewers whose useful comments assisting in clarifying the arguments in this paper. I am indebted to the many indigenous people I have worked with over the years in northern Australia. Sadly, many of these good friends who provided much of the source information, discussion and debate for this paper have passed away. I honor your knowledge; Lawutjirratjarra titu nyinamalpa.

\section{LITERATURE CITED}

Aboriginal Areas Protection Authority/Northern Land Council. 2004. An introduction to the Aboriginal people of the Daly River region: their history, land and sites. Report to the Daly River Expert Reference Group, Northern Land Council, Darwin, Australia.

Altman, J. C. 2000. The economic status of indigenous Australians. Centre for Aboriginal Economic Policy Research Discussion Paper 193. Australian National University, Canberra, Australia.

Altman, J. C., and P. J. Whitehead. 2003. Caring for country and sustainable indigenous development: opportunities, constraints, and innovation. Centre 
for Aboriginal Economic Policy Research Working Paper Number 20. Australian National University, Canberra, Australia.

Australian Bureau of Statistics. 2002. Australia's population. Government of Australia, Canberra, Australia.

Australian Fisheries Management Authority, and the National Oceans Office. 2003. Turtle and Dugong Catch Monitoring Workshop Report (Canberra, 2003). Australian Fisheries Management Authority, National Oceans Office, Canberra, Australia.

Baker, L., S. Woenne-Green, and Mutitjulu Community. 1993. Anangu knowledge of vertebrates and the environment. Pages 79-132 in J. R. W. Reid, J. A. Kerle, and S. R. Morton, editors. Uluru fauna: the distribution and abundance of vertebrate fauna of Uluru (Ayers Rock-Mt. Olga) National Park, Northern Territory. Australian National Parks and Wildlife Service, Canberra, Australia.

Balkanu Cape York Development Corporation. 2006. Overview of programs. Cape York Development Corporation, Cairns, Australia.

Berkes, F. 1999. Sacred ecology: traditional ecological knowledge and resource management. Taylor and Francis, Ann Arbor, Michigan, USA.

Bohensky, E., and T. Lynam. 2005. Evaluating responses in complex adaptive systems: insights on water management from the southern African millennium ecosystem assessment (SafMA). Ecology and Society 10(1):11. [online] URL: http:/ /www.ecologyandsociety.org/vol10/iss1/art11/.

Bowman, D. M. J. S., O. Price, P. J. Whitehead, and A. Walsh. 2001. The 'wilderness effect' and the decline of Callitris intratropica on the Arnhemland Plateau, Northern Australia. Australian Journal of Botany 49:665-672.

Bowman, D. M. J. S., Y. Zhang, A. Walsh, and R. J. Willimas. 2003. Experimental comparison of four remote sensing techniques to map tropical savanna fire-scars using Landsat-TM imagery. International Journal of Wildland Fire 12:341-348.

Brook, R. K., and S. M. McLachlan. 2005. On using expert-based science to "test" local ecological knowledge. Ecology and Society 10(2):3. [online]
URL: http://www.ecologyandsociety.org/vol10/iss2/ resp3/.

Brosius, P. J. 1997. Endangered forests, endangered people: environmentalist representations of indigenous knowledge. Human Ecology 25(1).

Burbidge, A. A., K. A. Johnson, P. J. Fuller, and R. I. Southgate. 1988. Aboriginal knowledge of the mammals of the central deserts of Australia. Australian Wildlife Research 15:9-39.

Burrows, N. D., A. A. Burbidge, P. J. Fuller, and G. Behn. 2006. Evidence of altered fire regimes in the western desert region of Australia. Conservation Science 5(3):272-284.

Charles Darwin University. 2007. Press release: United Nations Indigenous Knowledge University. Charles Darwin University, Darwin, Australia.

Christie, M. 1991. Aboriginal science for the ecologically sustainable future. Australian Science Teachers Journal 37(1):26-31.

Cochrane, M. J. 2005. The Djelk Ranger Program: an outsider's perspective. Centre for Aboriginal Economic Policy Research Working Paper Number 27. Australian National University, Canberra, Australia.

Cruikshank, J. 1998. The social life of stories: narrative and knowledge in the Yukon Territory. University of Nebraska Press, Lincoln, Nebraska, USA.

Cundill, G. N. R., C., Fabricius, and N. Mart. 2005. Foghorns to the future: using knowledge and transdisciplinarity to navigate complex systems. Ecology and Society 10(2):8. [online] URL: http:// www.ecologyandsociety.org/articles/1444.html.

Cunningham, A. B. 2001. Applied ethnobotany: people, wild plant use and conservation. Earthscan, London, UK.

Department of Environment and Heritage. 2006. National Heritage Trust Program. Government of Australia, Canberra, Australia.

Department of Environment and Conservation. 2007. A 100-year biodiversity conservation strategy for western Australia. Government of Western Australia, Perth, Australia. 
Dhimurru, L. M. A. C. 2006. Yolgnu Monuk Gapu Wanga Sea Country plan: a Yolngu vision and plan for sea country management in Northeast Arnhemland, Northern Territory. Nhulunbuy, Northern Territory, Australia.

Du Toit, J. T., B. H Walker, and B. M Campbell. 2003. Conserving tropical nature: current challenges for ecologists. Trends in Ecology and Evolution 19(1).

Duff, G.A., and R. W. Braithwaite. 1989. Fire and top end forest-past, present and future research. Pages 84-97 in B. R. Roberts, and G. L. Unwin, editors. Fire research in rural Queensland, University of Southern Queensland, Toowoomba, Australia.

Dyer, R., P. Jacklyn, I. Partridge, J. RussellSmith, and D. Williams. 2001. Savanna burning: understanding and using fire in northern Australia. Tropical Savannas Cooperative Research Centre for Tropical Savannas Management, Darwin, Northern Territory, Australia.

Finlayson, H. H. 1943. The red centre: man and beast in the heart of Australia. Angus and Robertson, Sydney, Australia.

Fisher, R., T. Vigilante, C. Yates, and J. RussellSmith. 2003. Patterns of landscape fire and predicted vegetation response in the North Kimberley region of Western Australia. International Journal of Wildland Fire 12:369-379.

Folds, R. 2001. Crossed purposes: the Pintupi and Australia's indigenous policy. University of New South Wales Press, Sydney, Australia.

Frazer, D. J., T. Coon, M. R Prince, R. Dion, and L. Bernatchez. 2006. Integrating traditional and evolutionary knowledge in biodiversity conservation: a population level case study. Ecology and Society 11(2):4. [online] URL: http://www.ecologyandsociety. org/articles/1754.html.

Gilchrist, G., M., Mallory, and F. Merkel. 2005. Can ecological knowledge contribute to wildlife management? Case studies of migratory birds. Ecology and Society 10(1)20. [online] URL: http:// www.ecologyandsociety.org/articles/1275.html.

Gupta, A. 1998. Postcolonial developments: agriculture in the making of modern India. Duke University Press, Durham, UK.
Holmes, J. 1996. Regional restructuring of the tropical savannas: impacts on lands, peoples and human settlements. Pages 5-19 in A. Ash, editor. The future of tropical savannas: an Australian perspective. Commonwealth Scientific and Industrial Research Organisation (CSIRO), Melbourne, Australia.

Hunn, E. S. 1999. The value of subsistence for the future of the world. Pages 23-36 In V.D. Nazarea, editor. Ethnoecology: situated knowledge/located lives. University of Arizona Press, Tucson, Arizona, USA.

Jinxiu, W. L., Huabin, H. Hongmao, and G. Lei. 2004. Participatory approach for rapid assessment of plant diversity through folk classification system in a tropical rainforest: case study in Xishuangbanna, China. Conservation Biology 18 (4):1139-1142.

Johannes, R. E. 2002. The renaissance of community-based marine resource management in Oceania. Annual Review of Ecological Systems 33:317-340.

Kimberley Land Council. 2006. Caring for country program. Kimberly Land Council, Broome, Australia.

Laird, S. A. 2002. Biodiversity and traditional knowledge: equitable partnerships in practice. Earthscan, London. UK.

Langton, M. 1999. Indigenous social, cultural economic and cultural issues in land, water and biodiversity conservation: a scoping study for WWF Australia. Volume 1. World Wide Fund for Nature, Sydney, Australia.

Majnep, I. S., and R. Bulmer. 1977. Birds of my Kalam country. Oxford University Press, Oxford, UK.

Martinez-Balleste, A., C. Martorell, and J. Caballero. 2006. Cultural or ecological sustainability? The effect of cultural change on Sabal palm management among the lowland Maya of Mexico. Ecology and Society 11(2):27. [online] URL: http:/ /www.ecologyandsociety.org/articles/1803.html.

McGrath, A. 1987. Born in the cattle. Allen and Unwin, Sydney, Australia. 
Merlan, F. 2004. Caging the rainbow: places, politics and Aborigines in a north Australian town. University of Hawaii Press, Honolulu, Hawaii, USA.

Morphy, H. 1991. Ancestral connections: art and an Aboriginal system of knowledge. University of Chicago Press, Chicago, Illinois, USA.

National Native Title Tribunal (NNTT). 2006. NNTT Web site. NNTT, Canberra, Australia.

North Australia Indigenous Land and Sea Management Alliance (NAILSMA). 2004. A structure for strategic development of the North Australia Indigenous Land and Sea Management Alliance (NAILSMA). Charles Darwin University, Darwin, Australia.

North Australia Indigenous Land and Sea Management Alliance (NAILSMA). 2006a. NAILSMA, Charles Darwin University, Darwin, Australia.

Available online at: http://www.nailsma.org.au.

North Australia Indigenous Land and Sea Management Alliance. 2006b. NAILSMA Forum Report 12, 2005. S. Johnson, editor. Charles Darwin University, Darwin, Australia.

Northern Australia Irrigation Futures (NAIF). 2006. The NAIF project. Available online at: http:// www.clw.csiro.au/naif/.

Northern Land Council. 2005. Caring for country unit strategic plan 2005. Northern Land Council, Darwin, Australia.

Pannell, S. 2005. "Getting the Mob In:" Indigenous initiatives in a new era of NRM in Australia. 11th International Symposium on Society and Resource Management. (Ostersund, 2005). Ostersund, Sweden.

Rose, D. B. 2000. Dingo makes us human: life and land in an Australian Aboriginal culture. Cambridge University Press, New York, New York, USA.

Rose, D. B. 2005. An indigenous philosophical ecology: situating the human. Australian Journal of Anthropology 16(3):294-305.
Ruddle, K. 2001. Systems of knowledge, dialogue, relationships and process. Environment, Development and Sustainability 2:277-304.

Russell-Smith, J., P. J Whitehead, R. J. Williams, and M. Flannigan. 2003a. Fire and savanna landscapes in northern Australia: regional lessons and global challenges. International Journal of Wildland Fire 12:5-6.

Russell-Smith, J., C. Yates, A. Edwards, G. E. Allan, G. D. Cook, P. Cooke, R. Craig, B. Heath, and R. Smith. 2003b. Contemporary fire regimes of northern Australia, 1997-2001: change since Aboriginal occupancy: challenges for sustainable management. International Journal of Wildland Fire 12:283-297.

Sluyter, A. 2002. Colonialism and landscape: postcolonial theory and applications. Rowman and Littlefield, London, UK.

Smyth, D., and S. Bahrdt. 2004. Case study No 4: developing and Aboriginal plan for the wet tropics NRM region in north Queensland. National Heritage Trust: Department of Environment and Heritage, Canberra, Australia.

Stanner, W. E. H. 1979. Durmugan: a Nangiomeri (1959). Pages 67-105 in W. E. H. Stanner, editor. White man got no dreaming: essays 1938-1973. Australian National University Press, Canberra, Australia.

Storrs, M. J., and P. M. Cooke. 2001. Caring for country: the development of a formalised structure for land management on Aboriginal lands within the Northern Land Council Region of the Northern Territory. Batchelor Institute, Darwin, Australia.

Taylor, J. 2006. Population and diversity: policy implications of emerging demographic trends. Centre for Aboriginal Economic Policy Research Discussion Paper 283. Australian National University, Canberra, Australia.

Tropical and Coastal Knowledge Research Hub. 2006. Charles Darwin University, Darwin, Australia. Available online at: http://track.gov.au/

Verran, H. 2002. A postcolonial moment in science studies: alternative firing regimes of environmental 
scientists and Aboriginal landowners. Social Studies of Science 32(5):729-762.

Whitehead, P. J., D. M. J. S. Bowman, N. Preece, F. Fraser, and P. Cooke. 2003. Customary use of fire by indigenous peoples in northern Australia: its contemporary role in savanna management. International Journal of Wildland Fire 12:415-425.

Wohling, M. 2000. Tangentyere landcare indigenous knowledge project report. Tangentyere Landcare and Environmental Health Unit, National Heritage Trust-Australian Government, Alice Springs, Australia.

Wohling, M. 2001. Ngaparrtji ngaparrtji nintilpayi: reciprocal thinking in indigenous land management. Pages 156-170 in R. Baker, J. Davies, and E. Young, editors. Working on country: contemporary indigenous management of Australia's lands and coastal regions. Oxford University Press, Melbourne, Australia.

Wohling, M., and the Daly River Aboriginal Reference Group. 2006. An indigenous management framework for the Daly River catchment: a report to the Northern Territory Government from the Daly River Aboriginal reference group. Northern Land Council, Darwin, Australia.

Wohling, M., and N. Gambold. 1997. Kiwirrkurra school indigenous knowledge camp: Yumari, October 1997. Central Land Council, Tangentyere Landcare and Environmental Health Unit, Alice Springs, Northern Territory, Australia.

Woinarski, J. C. Z. D., J. Milne, and G. Wanganeen. 2001. Changes in mammal populations in relatively intact landscapes of Kakadu National Park, Northern Territory, Australia. Austral Ecology 26:360-370.

Yibarbuk, D. 1998. Notes on traditional use of fire on the upper Cadell River. Pages 1-16 in $\mathrm{M}$. Langton, editor. Burning questions: emerging environmental issues for indigenous peoples in northern Australia. Centre for Indigenous Natural and Cultural Resource Management: Northern Territory University, Darwin, Australia.

Yibarbuk, D., P. J. Whitehead, J. Russell-Smith, D. Jackson, C. Godjuwa, A. Fisher, P. Cook, D. Choquenot, and D. M. J. S. Bowman. 2001. Fire ecology and Aboriginal land management in central
Arnhemland, Northern Australia: a tradition of ecosystem management. Journal of Biogeography 28:325-343. 